\title{
PROPOSAL FOR MODIFYING THE EMPIRICAL EQUATIONS OF SOIL DISPLACEMENT FOR GROUND SHOCK FROM BURIED EXPLOSIONS
}

\author{
LEO LAINE $^{1}$, OLA-PRAMM LARSEN ${ }^{2} \&$ JOOSEF LEPPÄNEN ${ }^{3}$ \\ ${ }^{1}$ LL Engineering AB, HÄRRYDA, Sweden \\ ${ }^{2}$ CAEwiz Consulting AS, OSLO, Norway \\ ${ }^{3}$ Chalmers University of Technology, Sweden
}

\begin{abstract}
This paper studies the empirical equations for predicting soil displacement from ground shock generated by buried or ground penetrating explosive charges. These equations were derived in the 1980s by Drake et al. (1983/1989) and then used in the conventional weapon loads software, TM 5-855-1, developed by US Army Research Engineers. AUTODYN simulations with a one-dimensional finite element wedge were conducted using a multi-material Euler formulation. Different sizes of explosive charges were simulated and the maximum soil displacement in dry sand was studied at different scaled distances $Z$. When comparing the results from AUTODYN simulations and empirical calculations on maximum soil displacement for charges varying from $0.125 \mathrm{~kg}$ to $512 \mathrm{~kg}$ in TNT weight and scaled distance $Z$ for each charge from 0.1 to $17 \mathrm{~m} / \mathrm{kg}^{1 / 3}$, AUTODYN simulations indicate that the empirical equations are conservative. Here, the soil model for dry sand from Sjöbo was used in the AUTODYN simulations and compared with dry sand parameters in empirical calculations. The Sjöbo sand's mechanical properties, including the equation of state (EOS), have been characterized from tri-axial tests performed by Norwegian Geotechnical Institute (NGI) in 2000. When comparing the results in a $\log -\log$ plot, with axes representing scaled distance and maximum soil displacement, it is seen that the results differ consistently. A proposal is made for scaled distances larger than $1 \mathrm{~m} / \mathrm{kg}^{1 / 3}$ of how the empirical equation for maximum displacement proposed by Drake et al. in 1989 can be modified with a modified scaling factor to receive a better fit with AUTODYN. For smaller scaled distance of less than $0.2 \mathrm{~m} / \mathrm{kg}^{1 / 3}$, the AUTODYN simulations show a saturation shape in the log-log plot. To receive an improved fit with the otherwise straight lines (one line for each charge size), which the original empirical equation was designed with, it is proposed to introduce an exponential factor that saturates the maximum displacements towards a smaller $Z$.
\end{abstract}

Keywords: ground shock, buried charge, dry sand, particle velocity, soil displacement, empirical equations, FE-simulations, AUTODYN, Conwep.

\section{INTRODUCTION}

The Swedish Civil Contingencies Agency (MSB) is responsible for the building regulations of the Swedish civil defence shelters. There are specific regulations for how the defence shelters are planned, built, equipped, and maintained [1]. One of many regulations states the load level that the shelters should be able to withstand: "The effect of a pressure wave corresponding to that produced by a $250 \mathrm{~kg}$ GP-bomb with 50 weight percent TNT which burst freely outside at a distance of 5.0 meters from the outside of the shelter during free pressure release". However, many of the shelters are designed as basements below ground level. Therefore, more knowledge is needed on how the ground shock propagates and attenuates over the scaled distances of $Z=0.1$ to $17 \mathrm{~m} / \mathrm{kg}^{1 / 3}$ and its effects on buried shelters.

During the Second World War extensive experiments and research were conducted on ground shock generated by high explosives [2]. This early work functions as a foundation for the empirical equations that are widely used to estimate the loading from ground shock [3][6]. The empirical equations for ground shock presented by Drake and Little [3] and Drake et al. [4] are the basis for the Conventional Weapons effects calculation program (ConWep) 
that US army engineers developed which includes the ground shock effects [6]. Here, in the simulations of ground shock from buried charges in dry sand with finite elements, the results differ compared to the empirical equations. In this paper, the difference in ground shock results between the empirical equations presented by Drake are compared with one dimensional wedge simulations for results from AUTODYN [7] simulations about maximum soil displacement and maximum particle velocity for charges varying from $0.125 \mathrm{~kg}$ to 512 $\mathrm{kg}$ in TNT weight and scaled distance $Z$ varied from 0.1 to $10 \mathrm{~m} / \mathrm{kg}^{1 / 3}$.

The paper is organized as follows; the Section 2 discusses how buried ground shock in dry sand is modelled in empirical equations and in AUTODYN simulations. Section 3 presents and compares the calculated results. Section 4 shows a proposal for modifying the empirical equations for a better fit with AUTODYN simulation results. Finally, Section 5 concludes the findings.

\section{MODELLING OF GROUND SHOCK IN DRY SAND}

The modelling of ground shock from buried explosions was done in such manner that the charges were buried deep enough to have full transmission of the energy into the soil material, in this case dry sand. In the empirical equations this means that the coupling factor $f$ was set equal to 1 .

\subsection{Empirical equations for ground shock calculations}

The empirical equations of particle velocity $u_{\mathrm{p} 0}$ and soil displacement $d_{0}$ for ground shock presented by Drake and Little [3] and Drake et al. [4] are described here.

\subsubsection{Empirical equations proposed by Drake and Little in 1983}

The maximum particle velocity and maximum displacement according to Drake and Little [3] is modelled with the following empirical equations

$$
u_{p 0-83}=48.768 f(2.520811 Z)^{-n},
$$

and

$$
d_{0-83}=60.4567 f \cdot W^{1 / 3} \frac{1}{c}(2.520811 Z)^{(-n+1)},
$$

where $f$ is the coupling factor, i.e. how deep the charge is buried, $W$ is the equivalent charge weight in $\mathrm{kg}$ TNT, $Z=z / W^{1 / 3}$ is the scaled distance, $z$ is the distance between the buried charge and the measurement position, and $n$ is the damping factor for the specific soil material. To model dry sand, the damping factor was set to $n=2.75$. Further details can be found in [3] and [11].

2.1.2 Empirical equations proposed by Drake et al. in 1989

The maximum particle velocity and maximum displacement according to Drake et al. [4] is modelled with following empirical equations

$$
\begin{gathered}
u_{p 0-89}=\frac{606.2}{\sqrt{\rho_{0}}}(Z)^{-\frac{3}{2}}, \quad Z \leq 0.155, \\
u_{p 0-89}=\frac{9906}{\sqrt{\rho_{0}}}\left(\frac{Z}{0.155}\right)^{-n}, Z>0.155,
\end{gathered}
$$

and 


$$
d_{0-89}=\frac{3.31}{c_{i}} W^{1 / 3}(Z)^{-2},
$$

where $W$ is the equivalent charge weight in $\mathrm{kg}$ TNT, $Z=z / W^{1 / 3}$ is the scaled distance, $z$ is the distance between buried charge and the measurement position, $n$ is the damping factor for the specific soil material, $\rho_{0}$ is the initial density of the soil, and $c_{\mathrm{i}}$ is the generalised seismic speed of the soil. To model dry sand, the damping factor was set to $n=2.75$, initial density to $\rho_{0}=1,674 \mathrm{~kg} / \mathrm{m}^{3}$, and the generalised seismic speed to $c_{\mathrm{i}}=350 \mathrm{~m} / \mathrm{s}$. Further details can be found in [4] and [11].

\subsection{AUTODYN 1-D wedge model}

One dimensional (1-D) wedge simulations are setup in AUTODYN [7] for simulations on maximum soil displacement and maximum particle velocity. The wedge is a representation of a 10-degree angle of explosive TNT, dry sand up to $Z=50 \mathrm{~m} / \mathrm{kg}^{1 / 3}$, see Fig. 1. The zoom on part of Fig. 1 shows the tip of the wedge with the TNT and the cell size and including a red diamond defining the detonation point. The studied scaled distance is from $Z=0.1$ to $10 \mathrm{~m} / \mathrm{kg}^{1 / 3}$. To apply initial atmospheric pressure in the dry Sjöbo sand, air was modelled for $Z>50 \mathrm{~m} / \mathrm{kg}^{1 / 3}$ with the initial in situ pressure $P_{\text {in situ. }}$. The multi-material Euler formulation is used in the cells. The explosive charge radius is modelled with uniform cell size, approximately $20-25$ cells. The uniform cell size continues up to $Z=2 \mathrm{~m} / \mathrm{kg}^{1 / 3}$. After this the cells are gradually coarsened up to $Z=100 \mathrm{~m} / \mathrm{kg}^{1 / 3}$. The used mesh resolution has been selected for optimality in computational performance and accuracy. The mesh sensitivity analysis on the ground shock results have been earlier analysed in prior simulations, for example [10], [11].

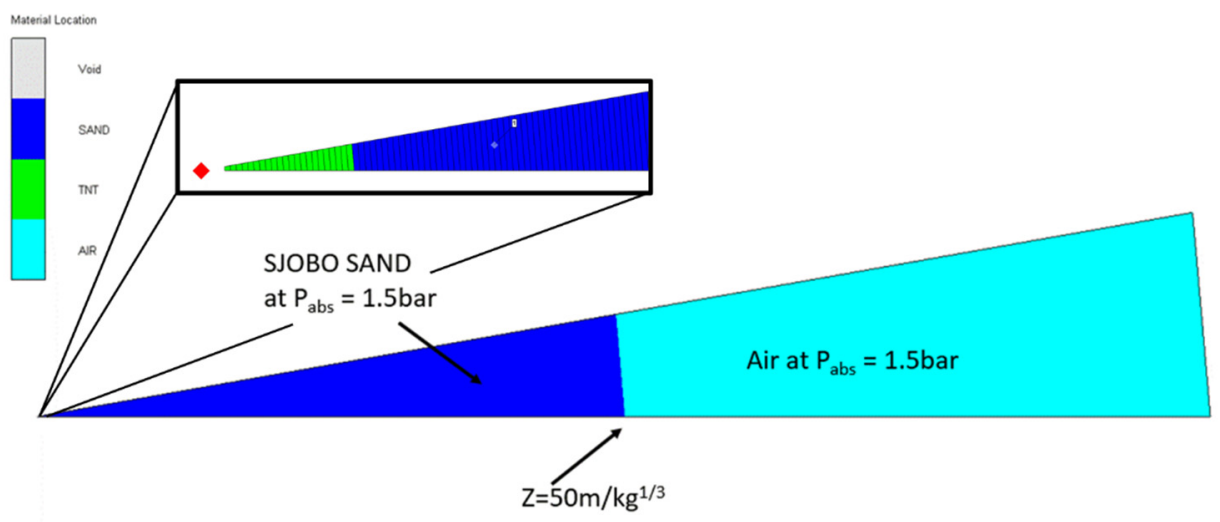

Figure 1: 1-D wedge model in AUTODYN showing the material location, including a zoom in of charge and cell size inside the charge.

Target points were defined at the following 40 radial scaled distances $Z=(0.1,0.2,0.3$, $0.4,0.5,0.6,0.7,0.8,0.9,1.0,1.1,1.2,1.35,1.45,1.6,1.75,1.95,2.15,2.35,2.6,2.85,3.15$, $3.45,3.8,4.2,4.6,5.05,5.55,6.1,6.75,7.4,8.15,8.95,9.85,10.85,11.9,13.1,14.4,15.85$, $17.45) \mathrm{m} / \mathrm{kg}^{1 / 3}$. Both fixed and moving target points were defined and used for measuring the sand displacement, particle velocity, and pressure in the simulations. The in-situ pressure is calculated as follows 


$$
P_{\text {in-situ }}(d)=P_{\text {atmospheric }}+\rho \cdot d \cdot g,
$$

where $P_{\text {atmospheric }}$ is the atmospheric pressure of $100 \mathrm{kPa}$ or 1 bar, $d$ is the vertical depth of burial distance in the soil with density $\rho$, and $g$ is the gravity constant. The in-situ pressure is $P_{\text {in-situ }}(d=0 \mathrm{~m})=1$ bar and for $P_{\text {in-situ }}(d=3 \mathrm{~m})=1.5$ bar.

\subsubsection{Material model for Sjöbo sand}

In this study, the soil material was modelled using a Porous Compaction Equation of State (EoS) with Mo granular strength. The mechanical properties from tri-axially tested "Sjöbo sand" from Sweden were used in the EoS and strength model, see Table 1. The input data for the Sjöbo sand EoS are given as Pressure $P$ and sound wave $c$, as a function of density $\rho$. The material model is characterised by the yield strength $Y$ as function of pressure $P$ and the shear modulus $G$ as a function of density $\rho$. Further information about the sand modelling for AUTODYN can be found in [8]-[11].

Table 1: Mechanical properties for Sjöbo Sand [8].

\begin{tabular}{|c|c|c|c|c|c|c|c|}
\hline \multicolumn{2}{|c|}{ EoS } & & & \multicolumn{2}{|c|}{ Strength } & \multirow[b]{2}{*}{$\begin{array}{c}\rho \\
\left(\mathrm{kg} / \mathrm{m}^{3}\right)\end{array}$} & \multirow[b]{2}{*}{$\begin{array}{c}G \\
(\mathrm{~m} / \mathrm{s})\end{array}$} \\
\hline $\begin{array}{c}\rho \\
\left(\mathrm{kg} / \mathrm{m}^{3}\right)\end{array}$ & $\begin{array}{c}P \\
(\mathrm{MPa})\end{array}$ & $\begin{array}{c}\rho \\
\left(\mathrm{kg} / \mathrm{m}^{3}\right) \\
\end{array}$ & $\begin{array}{c}c \\
(\mathrm{~m} / \mathrm{s})\end{array}$ & $\begin{array}{c}P \\
(\mathrm{MPa})\end{array}$ & $\begin{array}{c}Y \\
(\mathrm{MPa})\end{array}$ & & \\
\hline 1,674 & 0 & 1,674 & 265 & 0 & 0 & 1,674 & 76.9 \\
\hline 1,740 & 4.58 & 1,746 & 852 & 3.4 & 4.24 & 1,746 & 869.4 \\
\hline 1,874 & 15 & 2,086 & 1,722 & 34.9 & 44.7 & 2,086 & 4,032 \\
\hline 1,997 & 29 & 2,147 & 1,876 & 101.3 & 124 & 2,147 & 4,907 \\
\hline 2,144 & 59 & 2,300 & 2,265 & 184.7 & 226 & 2,300 & 7,769 \\
\hline 2,250 & 98 & 2,572 & 2,956 & 500 & 226 & 2,572 & 14,801 \\
\hline 2,380 & 179 & 2,598 & 3,112 & & & 2,598 & 16,571 \\
\hline 2,485 & 289 & 2,635 & 4,600 & & & 2,635 & 36,718 \\
\hline 2,585 & 450 & 2,641 & 4,634 & & & 2,641 & 37,347 \\
\hline 2,671 & 651 & 2,800 & 4,634 & & & 2,800 & 37,347 \\
\hline
\end{tabular}

\section{CALCULATION RESULTS AND COMPARISON}

First a comparison is made between the Drake 83 version of empirical equations and the 1-D AUTODYN simulation results, followed by a similar comparison for the Drake 89 version of empirical equations. The following charge weights $W$ of TNT were considered: $0.125 \mathrm{~kg}, 1 \mathrm{~kg}, 8 \mathrm{~kg}, 64 \mathrm{~kg}$, and $512 \mathrm{~kg}$.

\subsection{Drake 83 compared with AUTODYN}

To begin with, the particle velocity of the Drake 83 empirical equations are compared with AUTODYN results with an atmospheric pressure of 1 bar and buried at $3 \mathrm{~m}$ depth, resulting in 1.5 bar in situ pressure, see Fig. 2. There is a vertical offset between the Drake 83 and AUTODYN when comparing the results. The AUTODYN results for different charge sizes show that the particle velocity is only dependent on the scaled distance, which is expected 
from earlier knowledge. This is evidenced by that only the last line per pressure series is seen in the plot. For pressure 1 bar and 1.5 bar only the yellow and black solid line is seen which is the last plotted line for each series, respectively. At around scaled distance $Z=1 \mathrm{~m} / \mathrm{kg}^{1 / 3}$ the slope angle changes for the AUTODYN results, see Fig. 2. When analysing the results from not introducing any in-situ pressure in the sand (i.e. $P_{\text {in-situ }}=0$ bar), yields the same particle velocities up to $Z=1 \mathrm{~m} / \mathrm{kg}^{1 / 3}$. However, for $Z>1 \mathrm{~m} / \mathrm{kg}^{1 / 3}$, the simulations show a lower particle velocity when no in-situ pressure was used, and the AUTODYN results from $P_{\text {in-situ }}=0$ are omitted.

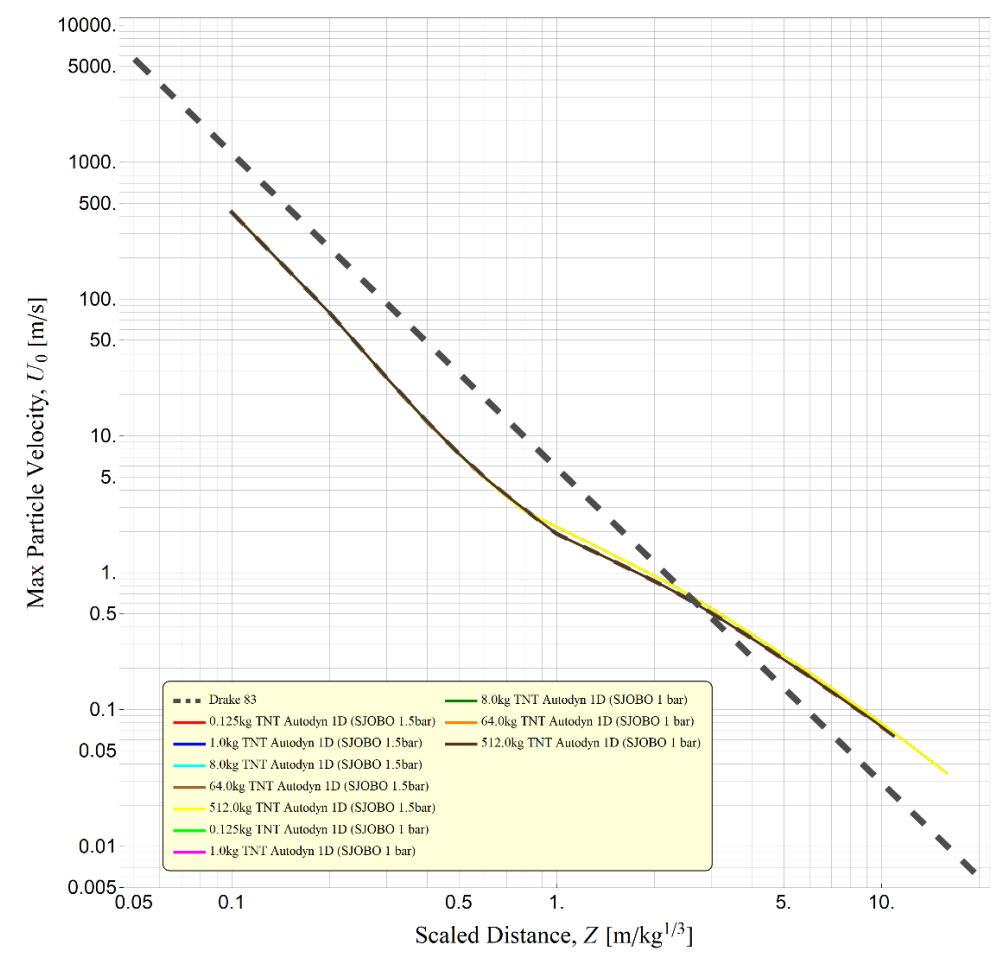

Figure 2: Maximum dry sand particle velocity $u_{\mathrm{p} 0}$ as a function of scaled distance $Z$ for buried charges $0.125,1,8,64$, and $512 \mathrm{~kg}$ TNT. Drake 83 compared with AUTODYN.

Secondly, when the sand displacement of Drake 83 is compared with AUTODYN results it shows that the charge size influences the magnitude of the displacement, see Fig. 3. That is, it is not only the scaled distance that influences the magnitude of sand displacement as it is for particle velocity. The dashed black lines represent Drake 83 and are given in different thicknesses. The thickest one represents the largest charge weight of $512 \mathrm{~kg}$ TNT, and the thinnest black dashed line represents the smallest charge size of $0.125 \mathrm{~kg}$ TNT. There is a major offset in magnitude and the curve's slope values differ between the Drake 83 and AUTODYN results, see Fig. 3.

To give a measure of the error between the empirical equations and the AUTODYN results a normalized mean square error $m s e_{d_{0}}$ of selected scaled distance range $Z_{i=1} \leq Z_{i} \leq Z_{i=n}$ and sum of all charge sizes $W_{j=1} \leq W_{j} \leq Z_{j=m}$ are used in the analyses 


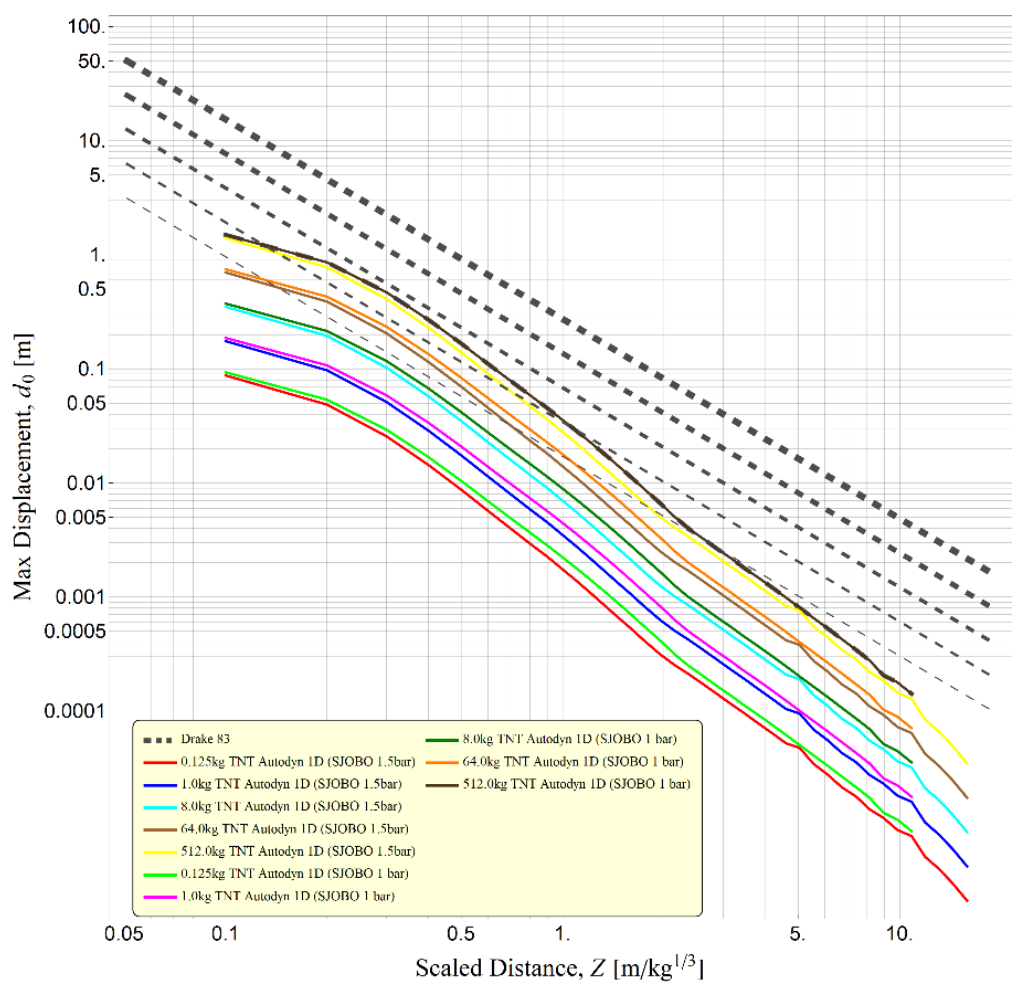

Figure 3: Maximum dry sand displacement $d_{0}$ as a function of scaled distance $Z$ for buried charges $0.125,1,8,64$, and $512 \mathrm{~kg}$ TNT for Drake 83 compared with AUTODYN.

$$
m s e_{d_{0}}=\frac{1}{n \cdot m} \sum_{W_{j=1}}^{W_{j=m}} \sum_{Z_{i=1}}^{Z_{i=n}}\left(\frac{d_{0-e m p(i, j)}-d_{0-s i m(i, j)}}{d_{0-e m p(i, j)}}\right)^{2} .
$$

The $m s e_{d_{0}}$ for Drake 83 and AUTODYN 1 bar results is 0.75 for the selected scaled distance range of $0.1 \mathrm{~m} / \mathrm{kg}^{1 / 3} \leq Z \leq 2 \mathrm{~m} / \mathrm{kg}^{1 / 3}$.

\subsection{Drake 89 compared with AUTODYN}

In Fig. 4, the particle velocity of Drake 89 empirical equations are compared with AUTODYN results with atmospheric pressure 1 bar and buried at $3 \mathrm{~m}$ depth resulting in 1.5 bar in situ pressure. Fig. 4 also shows the Drake 83 particle velocity and these are consequently higher in magnitude compared to Drake 89 . The Drake 89 is closer to the AUTODYN particle velocity results. At scaled distance $Z=0.1 \mathrm{~kg} / \mathrm{m}^{1 / 3}$, the magnitude on particle velocity is the same for Drake 89 and AUTODYN results.

In Fig. 5, the sand displacement of the Drake 89 empirical equations is compared with the AUTODYN results with an atmospheric pressure of 1 bar and buried at $3 \mathrm{~m}$ depth resulting in 1.5 bar in-situ pressure. Fig. 5 also shows the Drake 83 sand displacements and these are consequently higher in magnitude in comparison to those of Drake 89 . The slopes of the 


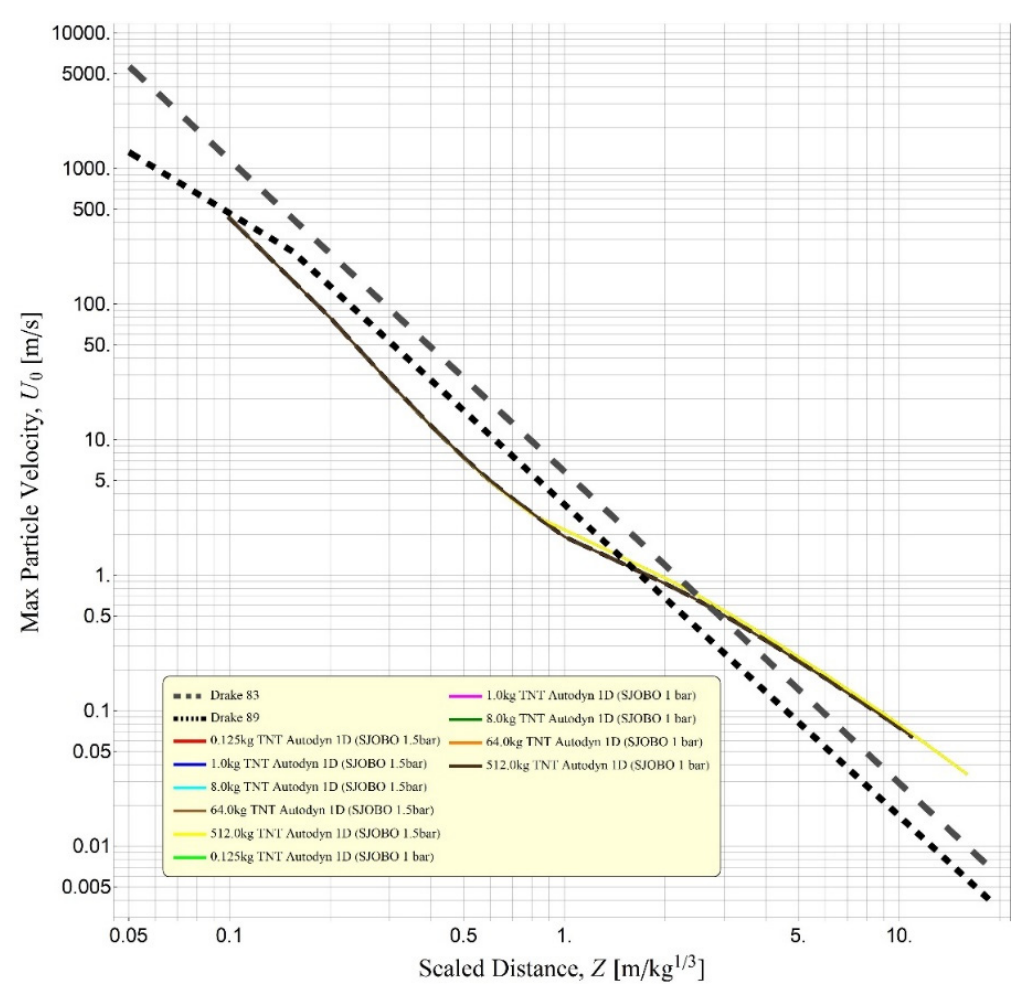

Figure 4: Maximum dry sand particle velocity $u_{\mathrm{p} 0}$ as a function of scaled distance $Z$ for buried charges $0.125,1,8,64$, and $512 \mathrm{~kg}$ TNT for Drake 83 and Drake 89 compared with AUTODYN.

Drake 83 and Drake 89 lines are different. The Drake 89 results are closer to the AUTODYN results on sand displacement. The $m s e_{d_{0}}$ is improved from 0.75 Drake 83 to 0.31 Drake 89 for the selected scaled distance range of $0.1 \mathrm{~m} / \mathrm{kg}^{1 / 3} \leq Z \leq 2 \mathrm{~m} / \mathrm{kg}^{1 / 3}$.

\section{PROPOSAL FOR MODIFYING THE EMPIRICAL EQUATIONS FOR DISPLACEMENT}

In general, when comparing the empirical equations with AUTODYN results, the Drake 89 empirical equations are closer. The maximum particle velocity of Drake 89 is not proposed to be modified as it seems accurate enough in comparison to simulation results. A proposal for how to modify the Drake 89 empirical equation for sand displacement will be hereby further studied.

\subsection{Proposal for modifying sand displacement of Drake 89}

Revisiting the empirical eqn (5) of Drake 89, which gives the sand displacement, it has been examined how it could be modified to fit the AUTODYN results better. A scaling factor of 0.49 is proposed for achieving a better fit between the simulation results and the empirical equations. 


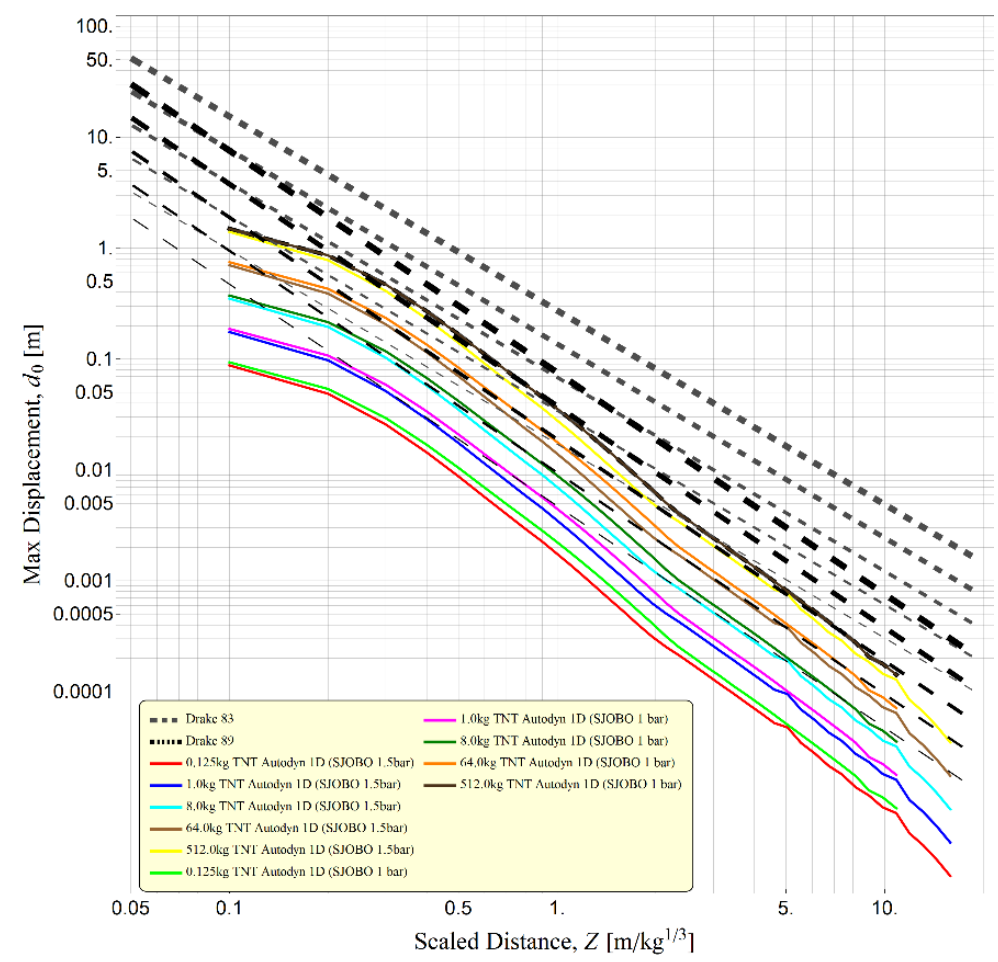

Figure 5: $\quad$ Maximum dry sand displacement $d_{0}$ as a function of scaled distance $Z$ for buried charges $0.125,1,5,8,10$, and $125 \mathrm{~kg}$ TNT for Drake 83 and Drake 89 compared with AUTODYN.

$$
d_{0-89 m 1}=0.49 \frac{3.31}{c_{i}} W^{1 / 3}(Z)^{-2} .
$$

The result of introducing the scaling factor of 0.49 is shown in Fig. 6. It shows that a simple modification gives a $m s e_{d_{0}}$ improvement from original Drake 89 of 0.31 to 0.04 with the scaling factor introduced for the selected scaled distances between $0.1 \mathrm{~m} / \mathrm{kg}^{1 / 3} \leq Z \leq 2$ $\mathrm{m} / \mathrm{kg}^{1 / 3}$.

However, for scaled distances $Z<0.2 \mathrm{~m} / \mathrm{kg}^{1 / 3}$, the AUTODYN simulations show a saturation shape in the log-log plot. Here it is proposed to use an exponential factor that saturates the maximum displacements towards a smaller $Z$. The exponential scaling factor is added to eqn (8) and becomes

$$
d_{0-89 m 2}=\left(1-e^{\left(-30 Z^{1.75}\right)}\right) 0.49 \frac{3.31}{c_{i}} W^{\frac{1}{3}}(Z)^{-2}
$$

The effect of introducing both an exponential scaling factor and a linear scaling factor as shown in eqn (9) is shown in Fig. 7. The proposed second modification gives a sse $_{d_{0}}$ improvement from 0.04 (eqn (8)) to 0.02 (eqn (9)) with the exponential scaling factor introduced for the selected scaled distances between $0.1 \mathrm{~m} / \mathrm{kg}^{1 / 3} \leq Z \leq 2 \mathrm{~m} / \mathrm{kg}^{1 / 3}$. 


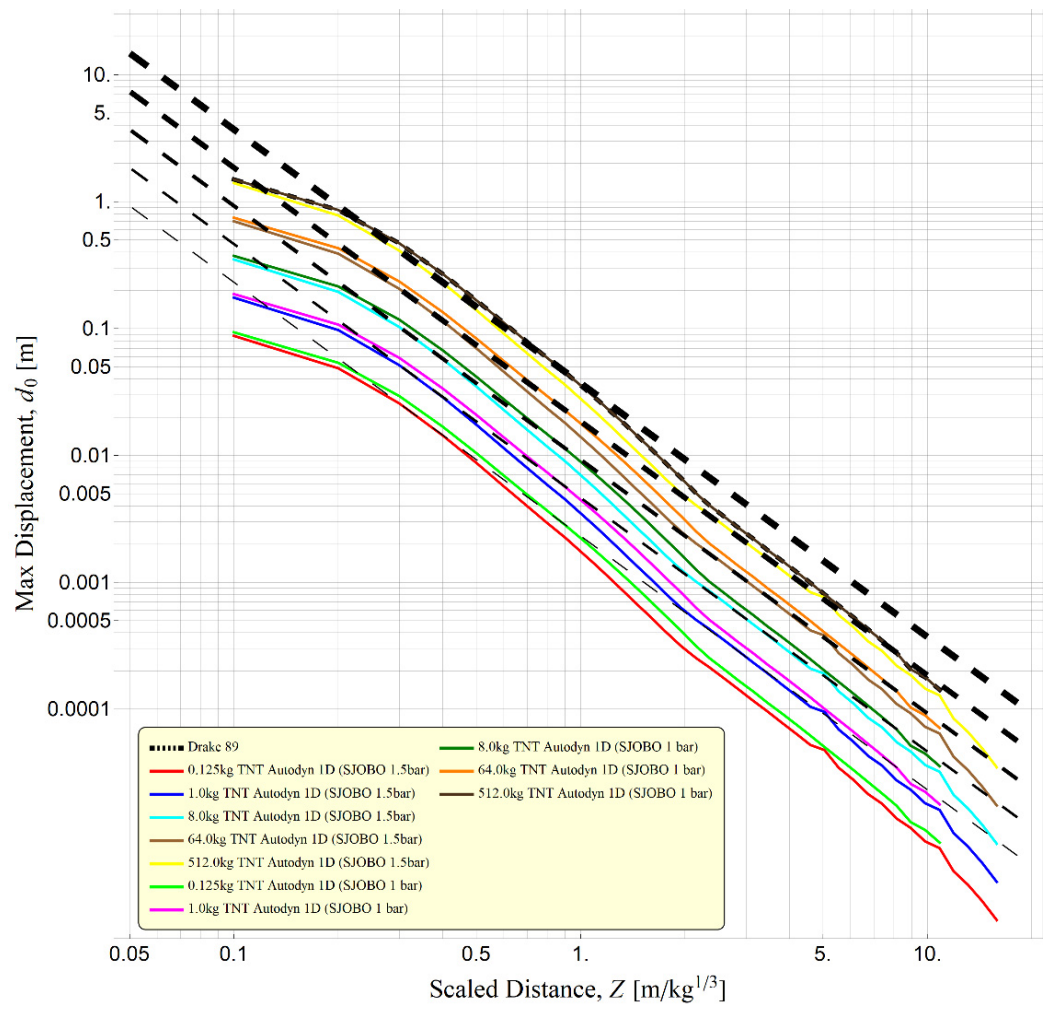

Figure 6: Maximum dry sand displacement $d_{0}$ as a function of scaled distance $Z$ for buried charges $0.125,1,8,64$, and $512 \mathrm{~kg}$ TNT using Modified scaling factor of 0.49 on eqn (5) for Drake 89 compared with AUTODYN.

To include the effect of depth of burial which influences the in-situ pressure, and the saturation effect for smaller scaled distances, the following modification is proposed

$$
d_{0-89 m 3}=\left(1-e^{\left(-30 Z^{1.75}\right)}\right)\left(0.49-\frac{d}{75}\right) \frac{3.31}{c_{i}} W^{\frac{1}{3}}(Z)^{-2},
$$

where $d$ is the vertical depth of burial in metres.

\section{CONCLUDING REMARKS}

The proposed modifications are based solely on one-dimensional FE-simulations with a crude simplification of real ground shock in dry sand. However, the major trends seen in the simplified analysis are expected to be found in accurately conducted experiments. Some of the major trends include that the magnitude of displacement is affected by the depth of burial. In addition, for small scaled distances, a saturation effect is expected to be seen on the displacements. These preliminary results from the ground shock simulations of dry sand, show that the Drake 89 empirical equations of maximum particle velocity and maximum displacement are closer to the AUTODYN results than Drake 83. The empirical equation for sand maximum displacement is modified with a linear scaling factor and an exponential scaling factor, resulting in reduced normalized mean squared error from 0.31 to 0.02 for the 


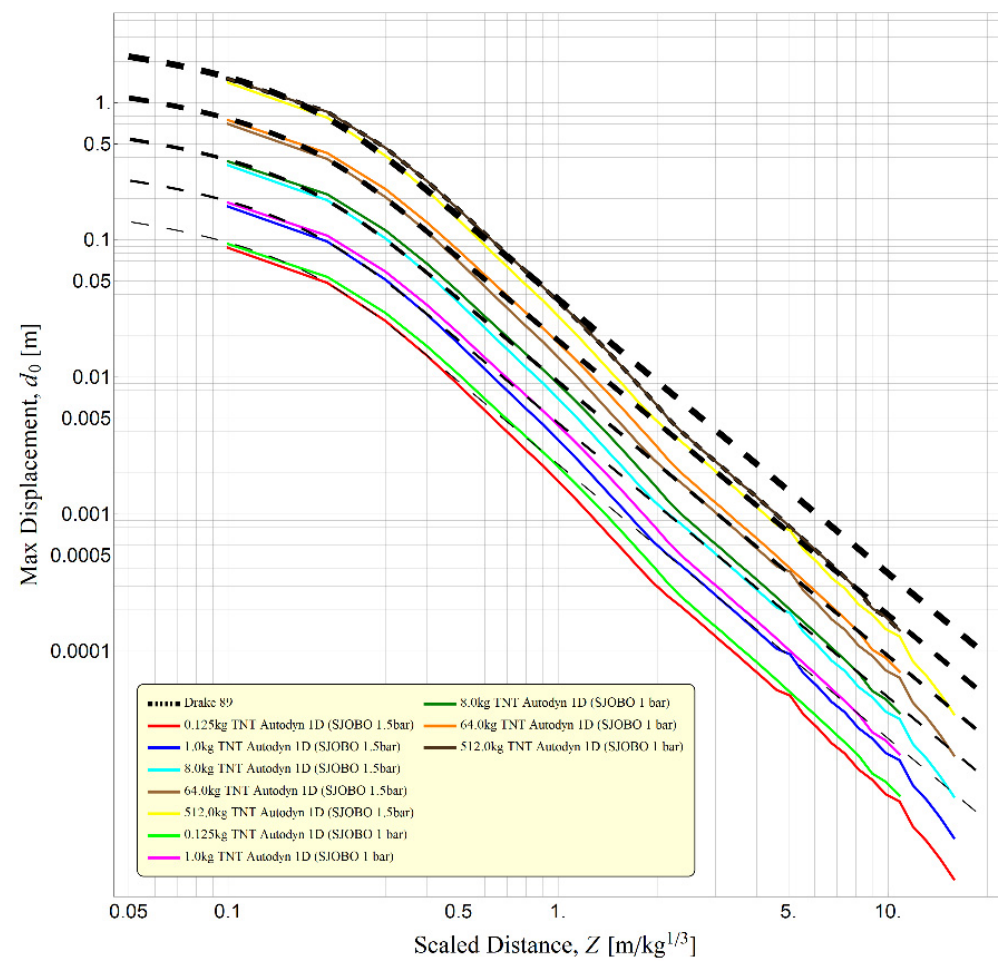

Figure 7: Maximum dry sand displacement $d_{0}$ as a function of scaled distance $Z$ for buried charges $0.125,1,8,64$, and $512 \mathrm{~kg}$ TNT modified with saturation/tapering for smaller scaled distances $Z$ by factor $\left(1-e^{\left(-30 Z^{1.75}\right)}\right)$ and scaling factor 0.49 on eqn (5) for Drake 89 compared with AUTODYN.

selected scaled distance range when compared with the AUTODYN simulation results. In future work, it is proposed to extend the simulation comparison with more soil materials and also introduce 2D simulations including soil layers with different impedances and a surface layer of air. These improved model features will better capture the ground shock reflections at the surface, and consequently yield better simulated estimates for the maximum soil displacement. In addition, new experimental results with characterized soil properties and accurate measurements would strengthen the derivation of improved empirical equations.

\section{ACKNOWLEDGEMENTS}

The authors acknowledge the support given by MSB and especially Lars Gråbergs. Additionally, members of the West Coast Sweden Shock Wave Group (WCSSWG), and especially Adj. Prof. Morgan Johansson, are highly acknowledged for their input.

\section{REFERENCES}

[1] Ekengren, B., Skyddsrum, SR 15 (Civil Defence Shelters SR 15). The Swedish Civil Contingencies Agency (MSB), Report No. MSB748, Karlstad: Sweden, 2018. 
[2] Lampson, C.W., Final Report on Effects of Underground Explosions, Div. 2, National Defence Research Committee of the US Office Scientific R\&D, NDRC Report No. A479, OSRD Report No. 6645, 1946.

[3] Drake, J.L. \& Little Jr, C.D., Ground shock from penetrating conventional weapons, interaction of non-nuclear munitions with structures. U.S. Air Force Academy: USA, 1983.

[4] Drake, J.L., Smith E.B. \& Blouin, S.E., Enhancements of the prediction of ground shock from penetrating weapons. 4th Int. Symp. on the Interaction of Non-Nuclear Munitions with Structures, Panama City Beach, FL, 1989.

[5] Bulson, P., Explosive Loading of Engineering Structures, CRC Press: London, 1997.

[6] ConWep, Collection of conventional weapons effects calculations based on TM 5-8551. Fundamentals of Protective Design for Conventional Weapons, U.S. Army Engineer Waterways Experiment Station: Vicksburg, USA 1992.

[7] Century Dynamics Inc., AUTODYN Theory Manual Revision 5.0, San Ramon, CA, 2004.

[8] Laine, L. \& Sandvik, A., Derivation of mechanical properties for sand. 4th AsianPacific Conference on Shock and Impact Loads on Structures, Singapore, 4, pp. 353360, 2001.

[9] Heyerdahl, H. \& Madshus, C., EOS-data for sand, tri-axial tests on sand from Sjöbo, Norges Geotekniske Institutt, NGI report 20001157-1, Oslo, Norway, 2000.

[10] Laine, L. \& Larsen, O.P., Implementation of equation of state for dry sand in AUTODYN. 83rd Shock and Vibration Symposium, Shock and Vibration Exchange (SAVE), New Orleans, LA, 2012.

[11] Laine, L., Markstötvåg (Ground Shock). MSB, Myndigheten för samhällsskydd och beredskap, Publ.nr MSB344, Karlstad, 2012.

www.msb.se/siteassets/dokument/amnesomraden/krisberedskap-och-civilt-forsvar/ befolkningsskydd/skyddsrum/referenslitteratur/markstotvag.pdf. 